\title{
VARIANT TERMINATION OF THE RIGHT TESTICULAR VEIN A CASE REPORT
}

Dr. Abdi S H M ${ }^{1}$, Sah Sanjay ${ }^{2}$

\section{ABSTRACT}

This case report pertains to a variant termination of the right testicular vein into a large lower tributary of the right renal vein, instead of opening into the inferior vena cava. Since the lower vein in which the right testicular vein opened did not join the inferior vena cava directly, therefore there is no real duplication of the right renal vein which has been found in some previous case reports. The right renal vein had its normal termination into the inferior vena cava. Embryological explanation of the anomalous termination of the right testicular vein has been given.

KEY WORDS: Gonadal veins, right renal vein, right testicular vein, inferior vena cava

1. Professor, Department of Anatomy, Universal college of Medical Sciences \& Teaching Hospital, Bhairahawa, Nepal

2. Assistant Professor, Department of Anatomy, Universal college of Medical Sciences \& Teaching Hospital, Bhairahawa, Nepal

For Correspondence

Prof.(Dr.) Syed HM Abdi

Department of Anatomy,

Universal College of Medical Sciences \& Teaching

Hospital, Bhairahawa, Nepal 


\section{INTRODUCTION:}

The gonadal veins, both testicular in the male and ovarian in the female are asymmetric in regard to their terminations. Normally the left gonadal vein opens into the left renal vein and the right gonadal vein opens into the inferior vena cava. In the males this anatomical difference is considered to be responsible for a generally weaker hemodynamics in the left testicular vein and consequently a greater incidence of varicocele on the left side. The present case becomes interesting because only a few reports of a right testicular vein terminating into the right renal vein are available in the literature.

\section{CASE REPORT:}

During the routine dissection in the department of anatomy UCMS, Bhairahawa Nepal, in the abdomen of a middle aged man, of average built, the right testicular vein was found to be terminating in a larger lower tributary of the right renal vein (Fig.1). This lower tributary joined the main radical of the right renal vein within $1.5 \mathrm{~cm}$ of the inferior vena cava. The right suprarenal vein was normally opening into the inferior vena cava and there were no other associated right or left sided vascular anomalies.

\section{DISCUSSION:}

Anson at el (1936) in a study of blood supply of 400 kidneys reported that the right renal vein rarely received tributaries other than those from the right kidney. ${ }^{1}$ However, Asla et al (2001) could find two cases of right gonadal veins draining into the right renal vein in 150 cadaveric dissections. ${ }^{2}$ Nim and Mohan Das (2010) also reported a case of right testicular vein draining into the right renal vein which, however, also received the right suprarenal vein a pattern similar to what is found on the left side normally. ${ }^{3}$ Bishwas et al (2006) reported a case of duplication of the right renal vein with the lower one receiving the right testicular vein as well. The right suprarenal vein apparently had a normal termination. Phalgunan et al (2012) in a study on 20 cadavers reported two cases of a right testicular vein opening into the right renal vein. In both of the reported cases more than one right renal vein existed. The upper vein received the right suprarenal while the lower one received an anomalous termination of the right testicular vein.

Gupta et al (2015) carried out 60 abdominal dissections, 40 males and 20 females and while they found no variations in the ovarian veins anomalies of right testicular vein were found in as many as $6(15 \%)$ out of the 40 male cadavers. In $4(10 \%)$ cadavers a single right testicular vein existed and drained into the right renal vein while in $2(5 \%)$ cadavers, double right testicular veins were found with one draining in the right renal and the other draining directly into the inferior venacava. ${ }^{6}$

Embryological explanations of the variations:
The segment of inferior venacava which receives the right renal vein is considered to develop from right sided subsupracardinal anastomosis. ${ }^{7}$ The right gonadal vein which develops from the caudal part of the right subcardinal vein also terminates in the same anastomotic channel. As such normally, the right testicular vein ends into the inferior vena cava. In the present variant case, however, the right gonadal vein is terminating into the right renal vein instead of opening into the inferior vena cava.

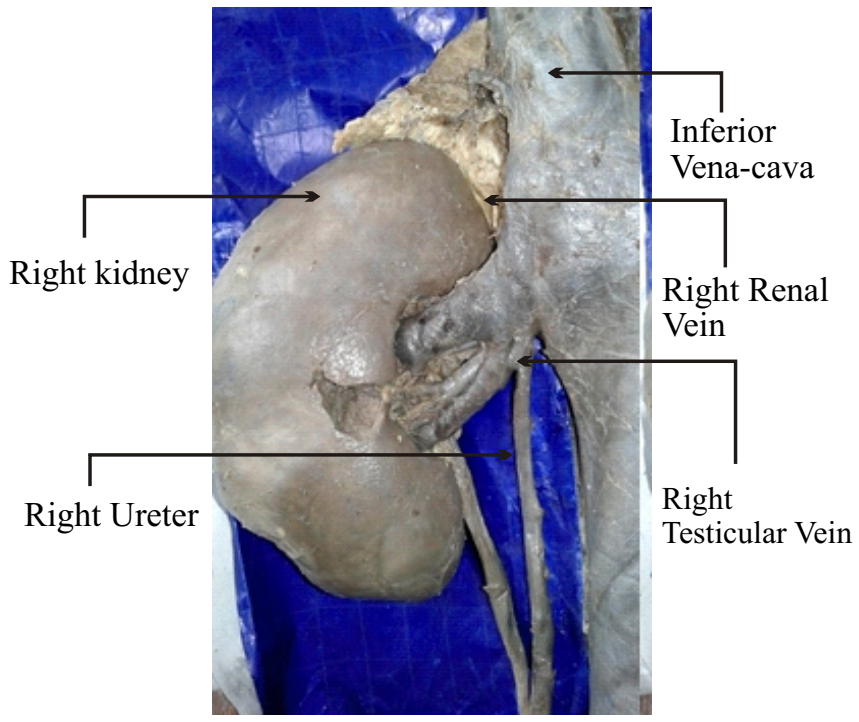

Figure 1: Termination of right testicular vein into right renal vein

\section{REFERENCES:}

1. Anson, B, Richardson GA, Minear WL. Variations in the number and arrangements of the renal vessels: A study of blood supply of 400 kidneys. j.Urol. 1936; 36:211-219

2. Asala S. Chaudhry SC, Masumbuko-Kahaba N, Bidoms M. Anatomical variations of human testicular blood vessels. Annals of Anatomy. 2001; 183(6):545-9.

3. Virender kumar Nim, Kalpana Mohandas. Abnormal Drainage of right testicular vein. JIMSA 2010.23(2.) 9192.

4. Sharmistha Bishwas, J. C. Chattopadhyay, H. Panicker, J. Anbalagan \& S. K. Ghosh. Variations in Renal and Testicular Veins. J. Anat. Soc. India 2006.55 (2) 69-71.

5. Vijisha Phalgunan, $N$ Mugunthan, Devi Jansi Rani, J. Anbalagan. A study of Renal and gonadal vein variations: 2012.1,(3) $125-128$

6. Raman Gupta, Anupa Gupta, Navita Aggarwal. Variations of gonadal veins: Embryological prospective and clinical significance. Journal of Clinical and Diagnostic Research. 2015. 9(2): 08-10.

7. Moore k. L., Persaud T.V.N. The Developing Human, eighth edition, Reed Elsevier india Pvt. Ltd. 2008: 288-291. 